\title{
Dichloroacetate treatment improves mitochondrial metabolism and reduces brain injury in neonatal mice
}

\author{
Yanyan Sun ${ }^{1,2, *}$, Tao $\mathrm{Li}^{1,2,3, *}$, Cuicui Xie ${ }^{2}$, Yaodong Zhang ${ }^{2,3}$, Kai Zhou ${ }^{2,4}$, Xiaoyang \\ Wang $^{1,5}$, Klas Blomgren ${ }^{4}$ and Changlian Zhu ${ }^{1,2,6}$ \\ ${ }^{1}$ Department of Pediatrics, Third Affiliated Hospital of Zhengzhou University, Henan, China \\ ${ }^{2}$ Center for Brain Repair and Rehabilitation, Institute of Neuroscience and Physiology, Sahlgrenska Academy, University of \\ Gothenburg, Gothenburg, Sweden \\ 3 Zhengzhou Children's Hospital, Zhengzhou, China \\ ${ }^{4}$ Department of Women's and Children's Health, Karolinska University Hospital, Karolinska Institutet, Stockholm, Sweden \\ ${ }^{5}$ Perinatal Center, Institute of Neuroscience and Physiology, Sahlgrenska Academy, University of Gothenburg, Gothenburg, \\ Sweden \\ ${ }^{6}$ Henan Provincial Key Laboratory of Child Brain Injury, Zhengzhou, China \\ * These authors have contributed equally to this work \\ Correspondence to: Changlian Zhu, email: changlian.zhu@neuro.gu.se \\ Keywords: apoptosis, autophagy, brain ischemia, mitochondria, pyruvate dehydrogenase, Pathology Section \\ Received: December 05, 2015 Accepted: April 22, $2016 \quad$ Published: May 03, 2016
}

\section{ABSTRACT}

The purpose of this study was to evaluate the effect of dichloroacetate (DCA) treatment for brain injury in neonatal mice after hypoxia ischemia (HI) and the possible molecular mechanisms behind this effect. Postnatal day 9 male mouse pups were subjected to unilateral HI, DCA was injected intraperitoneally immediately after $\mathrm{HI}$, and an additional two doses were administered at $24 \mathrm{~h}$ intervals. The pups were sacrificed $72 \mathrm{~h}$ after HI. Brain injury, as indicated by infarction volume, was reduced by $54.2 \%$ from $10.8 \pm 1.9 \mathrm{~mm}^{3}$ in the vehicle-only control group to $5.0 \pm 1.0 \mathrm{~mm}^{3}$ in the DCA-treated group at $72 \mathrm{~h}$ after HI $(p=0.008)$. DCA treatment also significantly reduced subcortical white matter injury as indicated by myelin basic protein staining $(p=0.018)$. Apoptotic cell death in the cortex, as indicated by counting the cells that were positive for apoptosis-inducing factor $(p=0.018)$ and active caspase-3 $(p=$ $0.021)$, was significantly reduced after DCA treatment. The pyruvate dehydrogenase activity and the amount of acetyl-CoA in mitochondria was significantly higher after DCA treatment and HI $(p=0.039, p=0.024)$. In conclusion, DCA treatment reduced neonatal mouse brain injury after $\mathrm{HI}$, and this appears to be related to the elevated activation of pyruvate dehydrogenase and subsequent increase in mitochondrial metabolism as well as reduced apoptotic cell death.

\section{INTRODUCTION}

Perinatal asphyxia-induced hypoxic ischemic brain injury (hypoxic-ischemic encephalopathy, HIE) is an important cause of neonatal death, and it occurs much more often in developing countries [1]. Survivors of perinatal asphyxia are often left with developmental impairments such as mental retardation and cerebral palsy $[2,3]$. Studies have revealed that secondary brain injury after hypoxia-ischemia (HI) is preceded by impairment of mitochondrial respiration, intra-mitochondrial accumulation of calcium, release of proapoptotic proteins from the mitochondrial intermembrane space, and downstream activation of caspase- 9 and caspase- $3[4,5]$. Interventions against perinatal $\mathrm{HI}$ brain injury, such as hypothermia $[6,7]$ and erythropoietin $[8,9]$, have shown promising results in reducing the incidence of neurological disabilities. However, these treatments have only been applied to full-term infants and are not successful in all cases. There is a pressing need for a better understanding of the mechanisms of brain injury and for conducting comparative and translational studies on how to improve 
HI-induced metabolic dysfunction, reduce neuronal cell death, increase cell survival, and promote brain regeneration and repair after perinatal brain injury [10].

HI deprives the brain of oxygen and glucose, and this results in an initial depletion of ATP that leads to rapid energy failure and necrotic cell death. The adenylate energy charge is restored rapidly during reperfusion and re-oxygenation. This is followed by a later secondary energy failure that lasts for several days [11] and initiates a cascade of biochemical events that results in delayed apoptotic cell death and autophagic cell death $[12,13]$. Persisting lactic acidosis has been shown to be associated with severe encephalopathy in neonatal HIE [14]. Therefore, treatments directed towards decreasing cerebral lactic acidosis and improving cerebral metabolism might ameliorate ischemic brain injury.

Dichloroacetate (DCA) is a small molecule inhibitor of pyruvate dehydrogenase kinase (PDK), which activates pyruvate dehydrogenase $(\mathrm{PDH})$ and facilitates mitochondrial oxidation of glucose-derived pyruvate and lactate via the tricarboxylic acid cycle to produce ATP. DCA readily crosses blood brain barrier [15], and it has been used for decades to treat children with mitochondrial disorders characterized by lactic acidosis [16-18]. Longterm DCA administration is shown to be generally safe and well tolerated in pediatric patients $[19,20]$. Previous studies found that DCA treatment improves the postischemic clearance rate of lactic acid and acidosis by activating the mitochondrial enzymes that transform pyruvate into acetyl-coenzyme $\mathrm{A}$ ( $\mathrm{AcCoA})$. This prevents the secondary energy failure [21], and the effect is more pronounced in the immature brain [22]. Furthermore, AcCoA is shown to be a metabolic master regulator of autophagy [23], and autophagic cell death contributes to HI brain injury [24]. Taken together, these previous studies indicate that DCA might have pronounced neuroprotective effects for neonatal HI brain injury. The purpose of this study was to investigate the effect of DCA treatment on brain injury in neonatal mice after $\mathrm{HI}$.
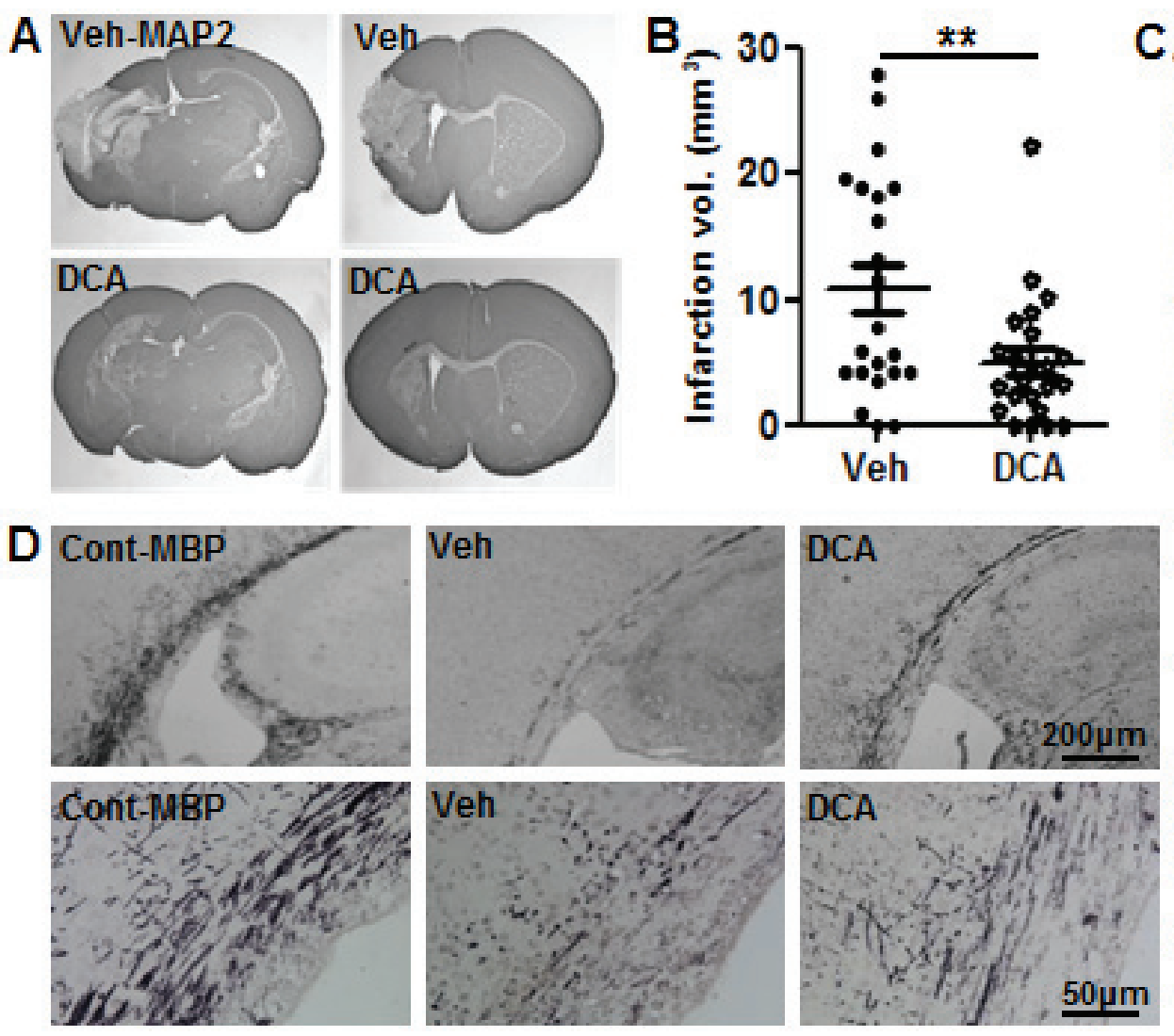
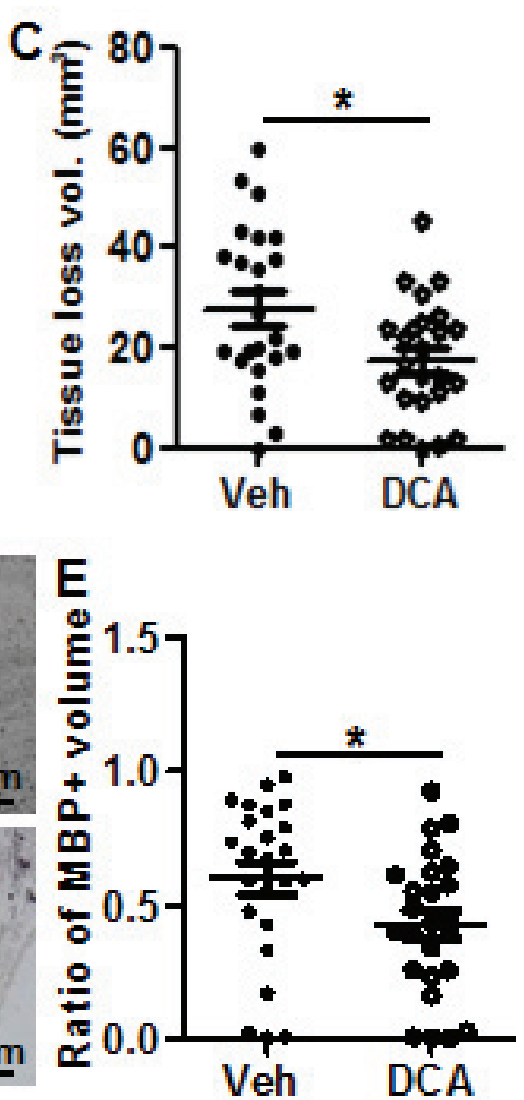

Figure 1: DCA treatment reduced brain injury after HI. A. Representative MAP2 staining from the dorsal hippocampus (left panels) and striatum (right panels) at $72 \mathrm{~h}$ post-HI in vehicle-treated (upper panels) and DCA-treated mice (lower panels). B. The infarction volume at $72 \mathrm{~h}$ after HI in DCA-treated $(n=25)$ and vehicle-treated mice $(n=24)$. C. The total tissue loss volume at $72 \mathrm{~h}$ after HI in DCAtreated and vehicle-treated mice. D. Representative MBP staining at the hippocampal level shows the myelin structure in the subcortical white matter of the ipsilateral hemisphere at $72 \mathrm{~h}$ after $\mathrm{HI}$ in vehicle-treated and DCA-treated mice as well as in normal control mice. The lower panel in E shows higher magnification of MBP-stained subcortical white matter. E. Quantitative analysis showed the tissue loss in the subcortical white matter in DCA-treated $(n=25)$ and vehicle-treated mice $(n=24) .{ }^{*} p<0.05, * * p<0.01$. 
RESULTS

\section{DCA treatment reduced HI brain injury in neonatal mice}

There were no treatment-related deaths. The body weight gain of the pups was from $4.43 \pm 0.44 \mathrm{~g}$ at postnatal day (PND) 9 to $4.94 \mathrm{~g} \pm 0.68 \mathrm{~g}$ at PND11 in the vehicle-treated group, and from $4.23 \pm 0.70 \mathrm{~g}$ at PND9 to $4.98 \mathrm{~g} \pm 0.89 \mathrm{~g}$ at PND11 in the DCA-treated group. HIinduced brain injury in neonatal mice was evaluated via immunohistochemistry staining for markers of gray matter (microtubule-associated protein 2, MAP2) and white matter (myelin basic protein, MBP) at $72 \mathrm{~h}$ after HI. The injury encompasses the cortex, hippocampus, striatum, and thalamus as indicated by the MAP2 staining. DCA treatment immediately after $\mathrm{HI}$ and then at $24 \mathrm{~h}$ and 48 $\mathrm{h}$ after HI was effective at reducing the severity of brain injury (Figure 1A). The gray matter injury, as indicated by the infarction volume calculated according to the measurement of positive MAP2 stained areas, was reduced by $54.2 \%$ from $10.8 \mathrm{~mm}^{3} \pm 1.9 \mathrm{~mm}^{3}$ in the vehicle-treated mice to $5.0 \mathrm{~mm}^{3} \pm 1.0 \mathrm{~mm}^{3}$ in the DCA-treated mice $(p=$ 0.008 ) (Figure 1B). The overall volume of brain tissue loss was reduced by $37.2 \%$ in DCA-treated mice compared to vehicle-treated mice $(p=0.037)$ (Figure 1C). Myelination was visualized in the sub-cortex by MBP staining at PND 12 , and the subcortical white matter displayed abnormal myelin structure in the brain hemisphere that is ipsilateral to the injury (Figure 1D). DCA treatment reduced the $\mathrm{HI}$-induced decrease in the MBP-positive volume in the subcortical white matter by $29.1 \%(p=0.018)$ compared with vehicle-treated mice (Figure 1E).

\section{DCA enhanced mitochondrial metabolism after $\mathrm{HI}$ in the neonatal mouse brain}

$\mathrm{PDH}$ activity was measured $24 \mathrm{~h}$ after $\mathrm{HI}$ in the brain cortical mitochondrial fraction in vehicle-treated and DCA-treated mice. PDH activity decreased significantly at $24 \mathrm{~h}$ after HI compared with that of non-HI controls in the vehicle-treated groups (PND10) $(p=0.0037)$, and DCA treatment prevented the PDH activity decline at $24 \mathrm{~h}$ after HI compared with vehicle-treated mice $(p=0.0396)$ (Figure 2A). As a result, AcCoA in the DCA-treated group increased significantly in the mitochondrial fraction compared with the vehicle-treated groups at $24 \mathrm{~h}$ after $\mathrm{HI}$ $(p=0.024)$ (Figure 2B). Lactate was also measured at 24 $\mathrm{h}$ after $\mathrm{HI}$ in the cortical homogenate, and lactate increased significantly at $24 \mathrm{~h}$ after HI compared with that of non-HI controls in the vehicle-treated groups $(p=0.0002)$ (Figure 2C).
Effect of DCA treatment on mitochondrial biogenesis in the neonatal mouse brain after $\mathrm{HI}$

To determine if DCA treatment has any effect on mitochondrial biogenesis, the brain mRNA expression levels of peroxisome proliferator-activated receptor $\gamma$ coactivator-1 $\alpha$ (Pgcl $\alpha$, which plays a key role in mitochondrial biogenesis and energy metabolism), mitochondrial transcription factor A (Tfam, which is a key activator of mitochondrial transcription and is a participant in mitochondrial genome replication), and nuclear respiratory factor 1 ( Nrfl, which functions as a transcription factor that activates some genes regulating cellular growth and mitochondrial respiration) were examined by RT-PCR at $6 \mathrm{~h}$ and $24 \mathrm{~h}$ after $\mathrm{HI}$ in the vehicle and the DCA treatment group (Figure 3A, 3B). $P g c-1 \alpha$ mRNA expression in the neonatal mouse brain was not significantly changed after HI compared with non-HI controls at $6 \mathrm{~h}$, but it decreased at $24 \mathrm{~h}$ after HI ( $p$ $=0.0152$ ) (Figure 3B). DCA treatment increased Pgc-1 $\alpha$ mRNA expression significantly at $6 \mathrm{~h}$ after HI compared with the vehicle treatment group $(p=0.034)$. Nrfl mRNA levels in the mouse brain did not begin to increase until 24 $\mathrm{h}(p=0.001)$ after HI in the DCA-treated group compared with the vehicle-treated group (Figure 3B). Tfam mRNA expression was significantly increased at $6 \mathrm{~h}$ after $\mathrm{HI}(p$ $<0.001)$, and DCA treatment had no significant effect on Tfam mRNA expression (Figure 3A). We checked the transcription of mitochondrial genes (mtDNA), and no significant change was observed regardless of whether or not the pups were treated with DCA or subjected to HI (Figure 3A, 3B). We further checked the mitochondriaencoded cytochrome c oxidase (COX) subunits I, II, and IV in the mitochondrial fraction of normal controls (Figure $3 \mathrm{C}$ ) and at $24 \mathrm{~h}$ after HI (Figure 3D). DCA treatment increased COX-IV at $24 \mathrm{~h}$ after HI $(p=0.016)$, but not COX-I and COX-II. The expression of these proteins did not change in the uninjured controls after DCA treatment.

\section{Effect of DCA treatment on mitochondrial fission and fusion in the neonatal mouse brain after $\mathrm{HI}$}

To examine the HI-induced changes in mitochondrial dynamics in the neonatal mouse brain and the possible influence of DCA treatment on these changes, we examined the transcription of the optic atrophy $1(\mathrm{Opal})$ and mitofusion ( $\mathrm{Mfn} 1)$ fusion genes and the dynamin-1-like protein (Drpl) fission gene as well as their protein expression in mitochondria at different time points after HI (Figure 4). There were no significant changes in these genes at $6 \mathrm{~h}$ after HI compared with the controls (Figure 4A), but there was decreased transcription of Opal ( $p=0.009)$ and Drpl $(p=0.001)$ at $24 \mathrm{~h}$ after HI. DCA treatment prevented HI-induced reduction of $M f n 1$ $(p=0.033)$ and $\operatorname{Drpl}(p=0.011)$ at $24 \mathrm{~h}$ after HI (Figure 

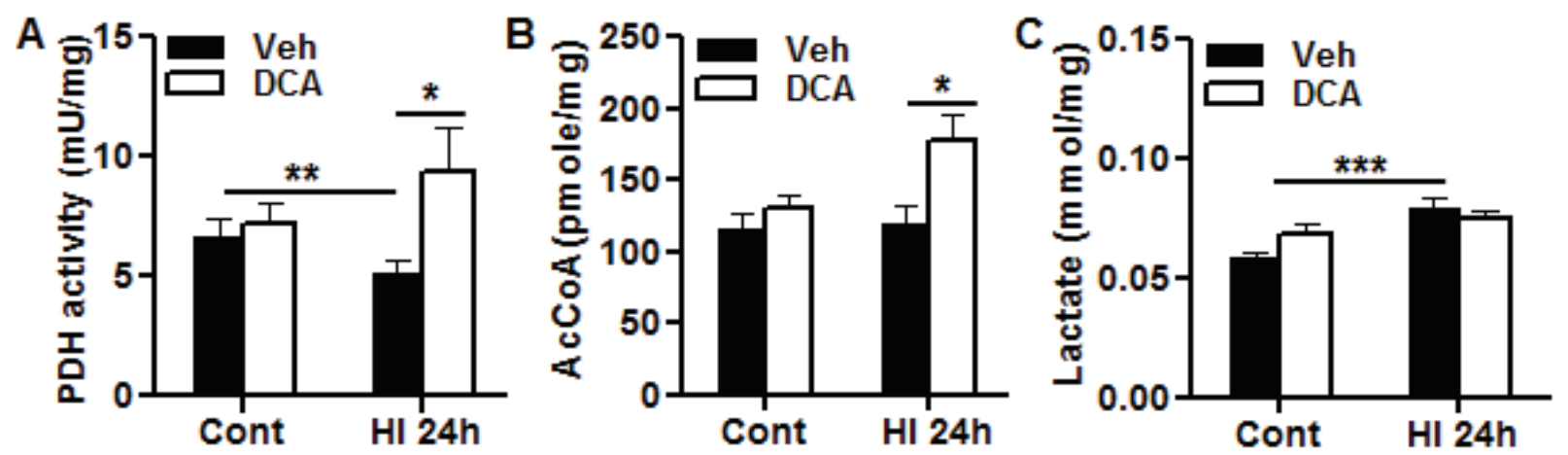

Figure 2: Effect of DCA treatment on brain mitochondrial metabolism. Bar graphs show the effects of DCA treatment on control (Cont) at PND10 and at $24 \mathrm{~h}$ post-HI. A. Pyruvate dehydrogenase (PDH) activity assays in the brain cortical mitochondrial fraction. B. Acetyl-coenzyme A (AcCoA) concentrations in the brain cortical mitochondrial fraction. C. Lactate concentration in the brain cortical total homogenate. For all three assays, $\mathrm{n}=8$ for vehicle group, $n=7$ for DCA group. ${ }^{*} p<0.05,{ }^{* *} p<0.01, * * * p<0.001$.
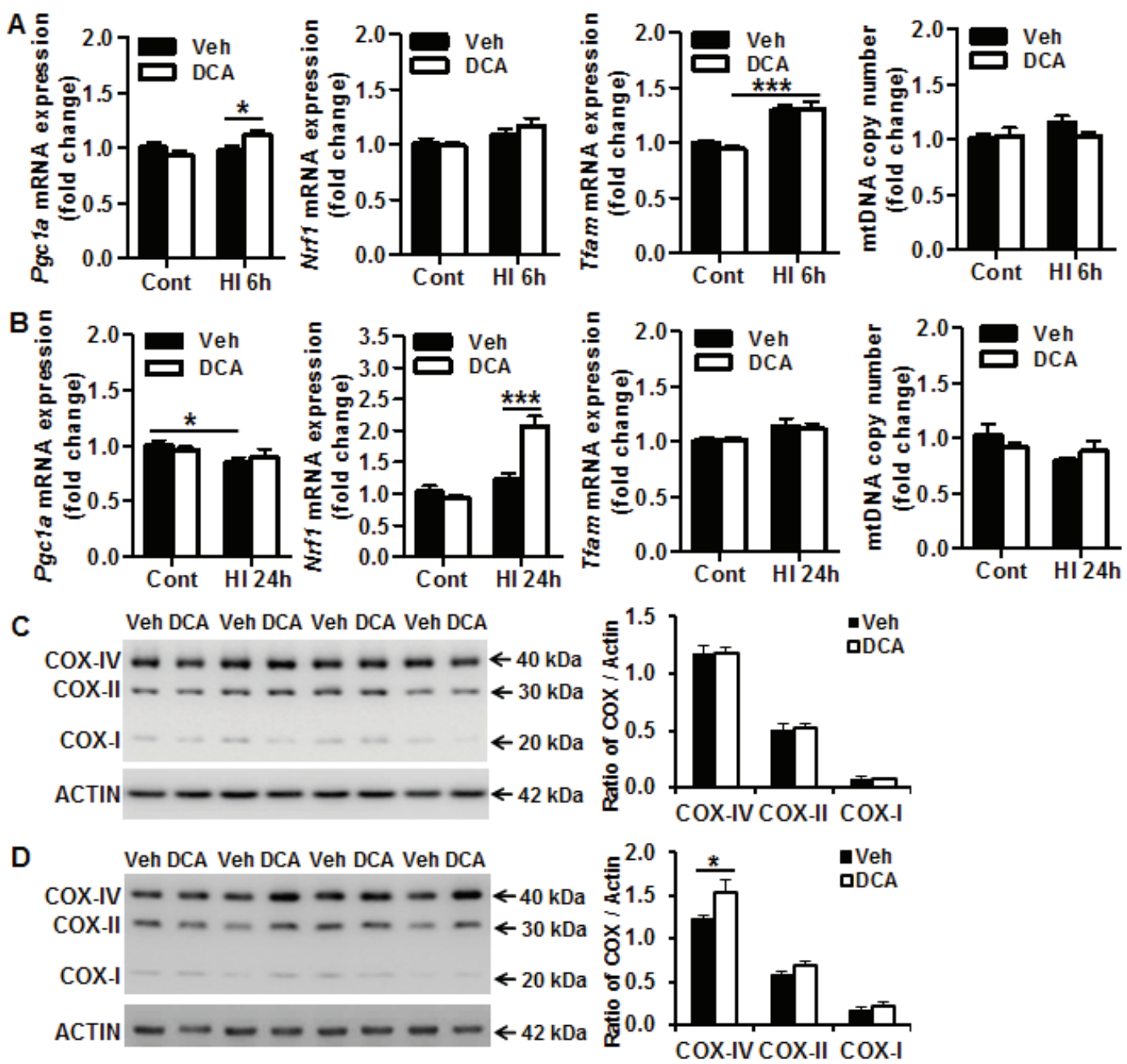

Figure 3: Effect of DCA treatment on brain mitochondrial biogenesis. A. mRNA expression of mitochondrial biogenesisrelated genes (Pgcl $\alpha, \mathrm{Nrf1}$, Tfam) and mtDNA copy number (mtDNA) in DCA-treated and vehicle-treated mice at $6 \mathrm{~h}$ after HI. B. mRNA expression of mitochondrial biogenesis-related genes (Pgcl $\alpha, N r f 1, T f a m)$ and mtDNA copy number (mtDNA) in DCA-treated and vehicletreated mice at $24 \mathrm{~h}$ after HI. For all of the above assays, $n=11$ for the vehicle control, $n=13$ for the DCA control, $n=6$ for the $6 \mathrm{~h} \mathrm{HI}$ and $6 \mathrm{~h}$ DCA groups, $n=8$ for the $24 \mathrm{~h} \mathrm{HI}$ vehicle group, and $n=7$ for the $24 \mathrm{~h}$ HI DCA group. C. Immunoblotting of COX-I, II, and IV in the mitochondrial fraction of normal controls treated with vehicle (Veh) or DCA. D. Immunoblotting of COX-I, II, and IV in the mitochondrial fraction at $24 \mathrm{~h}$ after HI showing that and DCA treatment increased COX-I, II, IV expression, and this was more pronounced with COX-IV. $* p<0.05, * * * p<0.001$. 
4B). We further checked the protein expression of these genes and found that OPA1 and phospho-DRP1 (Ser637) (P-DRP1) all began to decrease at $6 \mathrm{~h}$ after HI (Figure 4C) and continued to decrease at $24 \mathrm{~h}$ after HI. The cleavage product of OPA 1 increased significantly at $24 \mathrm{~h}$ after HI $(p=0.024)$. The increased cleavage product of OPA1 indicates that mitochondrial fusion was reduced, and the decrease in P-DRP1 reduces inhibition on mitochondrial fission and indicates that $\mathrm{HI}$ insult caused an increase in mitochondrial fission. However, DCA treatment did not prevent HI-induced reduction of P-DRP1 or cleavage of OPA1 in mitochondria (Figure 4D).
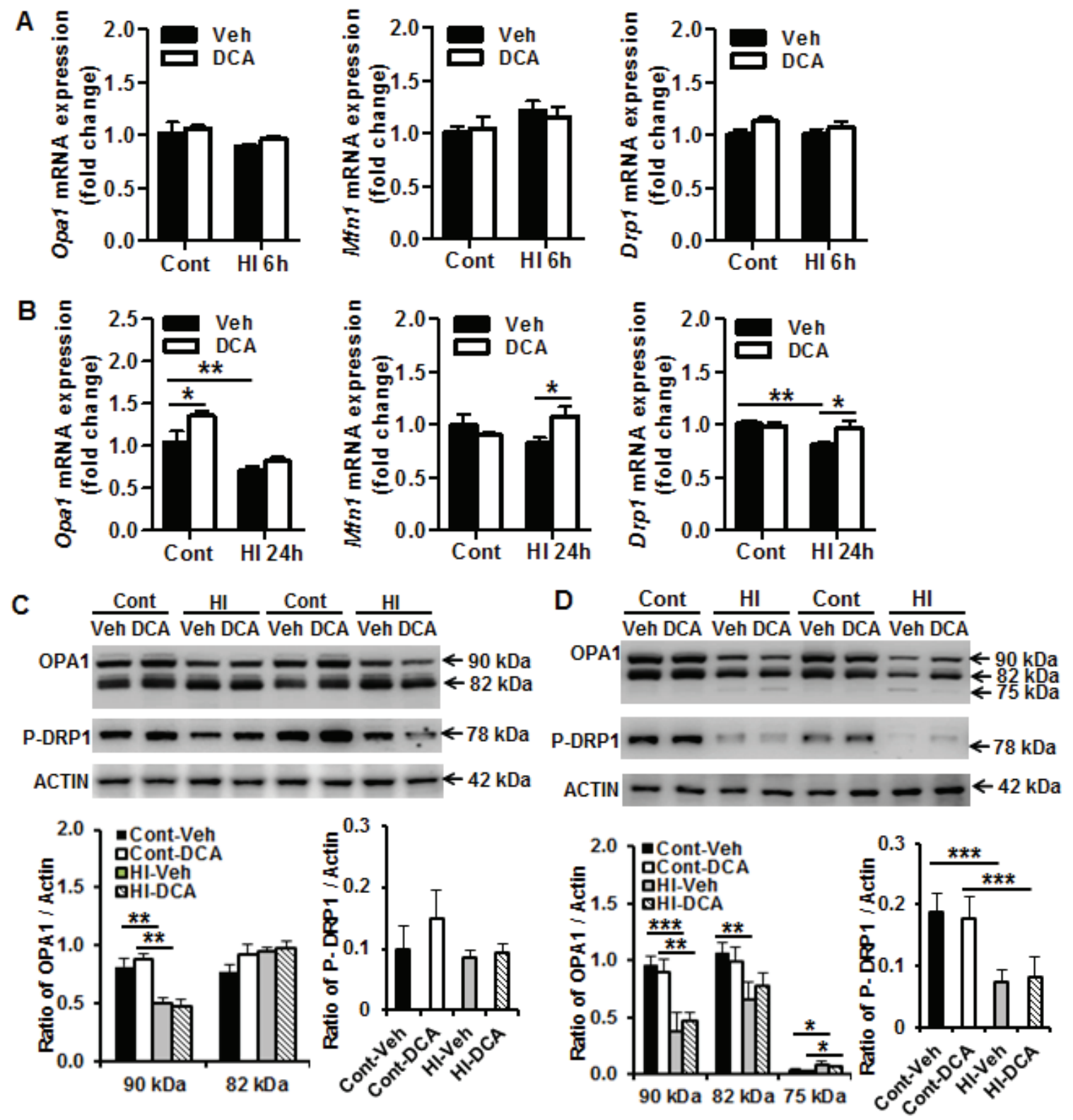

Figure 4: Effect of DCA treatment on brain mitochondrial fission and fusion. A. The mRNA expression levels of the mitochondrial fusion (Mfnl, OPAl) and fission (Drpl) genes in the mouse brain were quantified by RT-qPCR at $6 \mathrm{~h}$ after HI. B. The mRNA expression levels of the mitochondrial fusion (Mfn1, OPA1) and fission (Drpl) genes in the mouse brain were quantified by RT-qPCR at $24 \mathrm{~h}$ after HI. $n=5$ for the vehicle control, $n=6$ for the DCA control at $6 \mathrm{~h}, n=6$ for the $6 \mathrm{~h} \mathrm{HI}$ and $6 \mathrm{~h}$ DCA groups; $n=6$ for the vehicle control, $n=7$ for the DCA control at $24 \mathrm{~h}, n=8$ for the $24 \mathrm{~h} \mathrm{HI}$ vehicle group, and $n=7$ for the $24 \mathrm{~h}$ HI DCA group. C. Immunoblotting of OPA1, MFN1, and P-DRP1 in the mitochondrial fraction of normal control (Cont) and $6 \mathrm{~h}$ after HI treated with vehicle (Veh) or DCA. The $90 \mathrm{kDa}$ upper band of OPA1 was decreased significantly at $6 \mathrm{~h}$ after HI, and DCA treatment did not prevent the reduction ( $n=6 /$ group). D. Immunobloting of OPA1, and P-DRP1 in normal controls and $24 \mathrm{~h}$ after HI treated with vehicle or DCA. The expression of these proteins decreased significantly at $24 \mathrm{~h}$ after $\mathrm{HI}$ in the mitochondrial fraction. The $75 \mathrm{kDa}$ cleavage band of OPA 1 increased significantly after HI, and DCA treatment has no significant effect on OPA1 cleavage at $24 \mathrm{~h}$ after $\mathrm{HI}(n=6 /$ group $) .{ }^{*} p<0.05, * * p<0.01$. 


\section{DCA treatment reduced autophagy in neonatal mouse brain after $\mathrm{HI}$}

Autophagic cell death is another important contribution to neonatal brain injury [24, 25]. Autophagy activity was detected by immunoblotting for microtubuleassociated protein 1 light chain 3 (LC3)-II and SQSTM1/ p62 (a protein known to be selectively degraded by autophagy) in the brain cortical mitochondrial fraction at $24 \mathrm{~h}$ after HI (Figure 5A). The quantification of the LC3-II band $(16 \mathrm{kDa})$ did not show a significant increase in the ipsilateral brain hemisphere compared to the contralateral brain hemisphere, and no difference between vehicle and DCA treatment groups was detected (Figure 5B). SQSTM, however, decreased in the ipsilateral brain hemisphere compared to the contralateral hemisphere in the vehicletreated mice, and DCA treatment prevented the HI-induced SQSTM decrease compared to the vehicle-treated group ( $p$ $=0.041)$ (Figure 5C). This provides indirect evidence that DCA treatment reduces autophagy activity in the mouse brain after HI.

DCA treatment reduced caspase-independent apoptotic cell death in the neonatal mouse brain after $\mathrm{HI}$

Compared to the adult mouse, both the apoptosisinducing factor (AIF)-dependent and AIF-independent apoptotic cell death pathways are more pronounced in the immature brain in HI-induced brain injury [26].
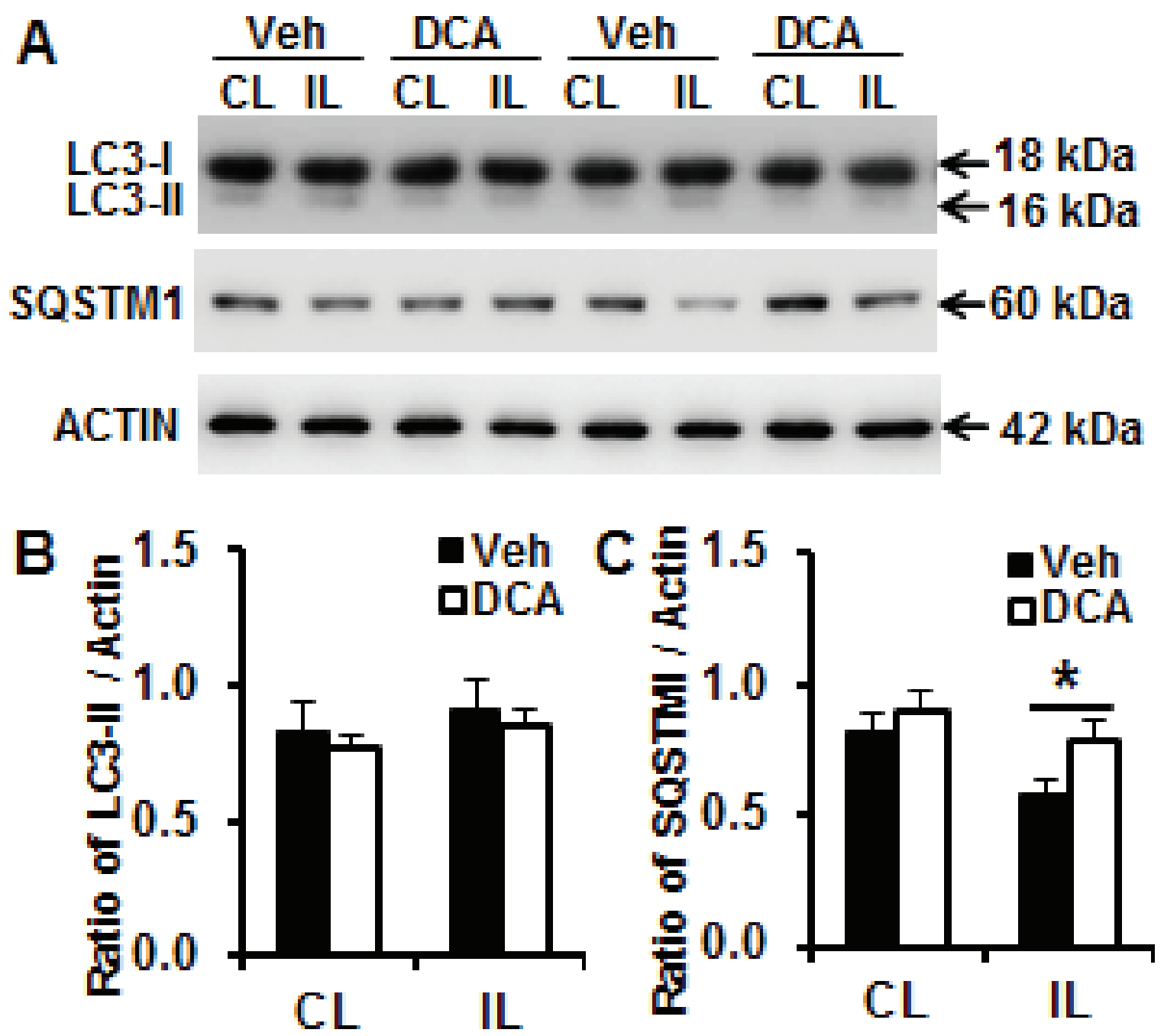

Figure 5: DCA treatment reduced autophagy activity in the mouse brain after HI. A. Representative immunoblotting pictures show the expression of LC3 and SQSTM1 in the brain mitochondrial fraction at $24 \mathrm{~h}$ after HI. B. Quantification of LC3-II immunoblotting normalized to actin in the ipsilateral hemisphere (IL) compared to the contralateral hemisphere (CL) in the vehicle and DCA treatment group. C. Quantification of SQSTM1 immunoblotting in the ipsilateral hemisphere in the vehicle and DCA treatment groups. $n=7$ for the vehicle group and $n=6$ for the DCA group. ${ }^{*} p<0.05$. 
Caspase-independent apoptotic cell death, as indicated by AIF nuclear translocation, was investigated in the cortex in the mouse brain. AIF nuclear translocation was increased at the examined time points after HI (Figure $6 \mathrm{~A})$, and DCA treatment reduced AIF release from the mitochondria and translocation to the nucleus in the mouse brain cortex region at $24 \mathrm{~h}$ after HI, which was when caspase-independent apoptotic cell death reached its peak level ( $p=0.009$ ) (Figure 6B). Immunoblotting of the brain mitochondrial fraction at $24 \mathrm{~h}$ after HI showed reduced AIF in the ipsilateral hemisphere compared to the contralateral hemisphere (Figure 6C), and this was more pronounced in the vehicle treatment group than the DCA treatment group (25.9\% vs. $12.7 \%$, respectively) (Figure 6D).

\section{DCA treatment reduced caspase-dependent apoptotic cell death in the neonatal mouse brain after $\mathrm{HI}$}

Caspase-dependent apoptotic cell death was investigated by applying immunostaining for the active form of caspase-3 in the injured brain areas after $\mathrm{HI}$ in PND9 mice (Figure 7A). DCA treatment reduced caspase-3 activation in the cortex at $24 \mathrm{~h}(p=0.021)$ after
HI - when the apoptotic cell death reaches its peak [27] - compared to the vehicle treatment group (Figure 7B). As a sensitive marker of caspase-dependent apoptosis cell death, caspase- 3 activity was increased as early as $6 \mathrm{~h}$ after $\mathrm{HI}$ and reached its highest level at $24 \mathrm{~h}$ after HI. DCA treatment significantly reduced caspase- 3 activation at 24 $\mathrm{h}(p=0.021)$ after HI compared to the vehicle treatment group (Figure 7C).

\section{DISCUSSION}

DCA has been used safely for decades to reduce cerebral lactate in children with genetic mitochondrial diseases [20], and it has been shown to resolve cerebral lactic acidosis to a greater degree in the immature brain [22]. Experimental studies have shown that DCA treatment also prevents secondary energy failure at early reperfusion after cerebral ischemia [28] and that it reduces ischemic brain injury in adult rats [29]; however, it is unknown whether or not it is also neuroprotective in HI-induced neonatal brain injury in rodents. In this study, we show for the first time that DCA treatment after HI increases mitochondrial PDH activity and AcCoA production, decreases autophagy and apoptotic neuronal cell death, and has a neuroprotective effect in neonatal mice.

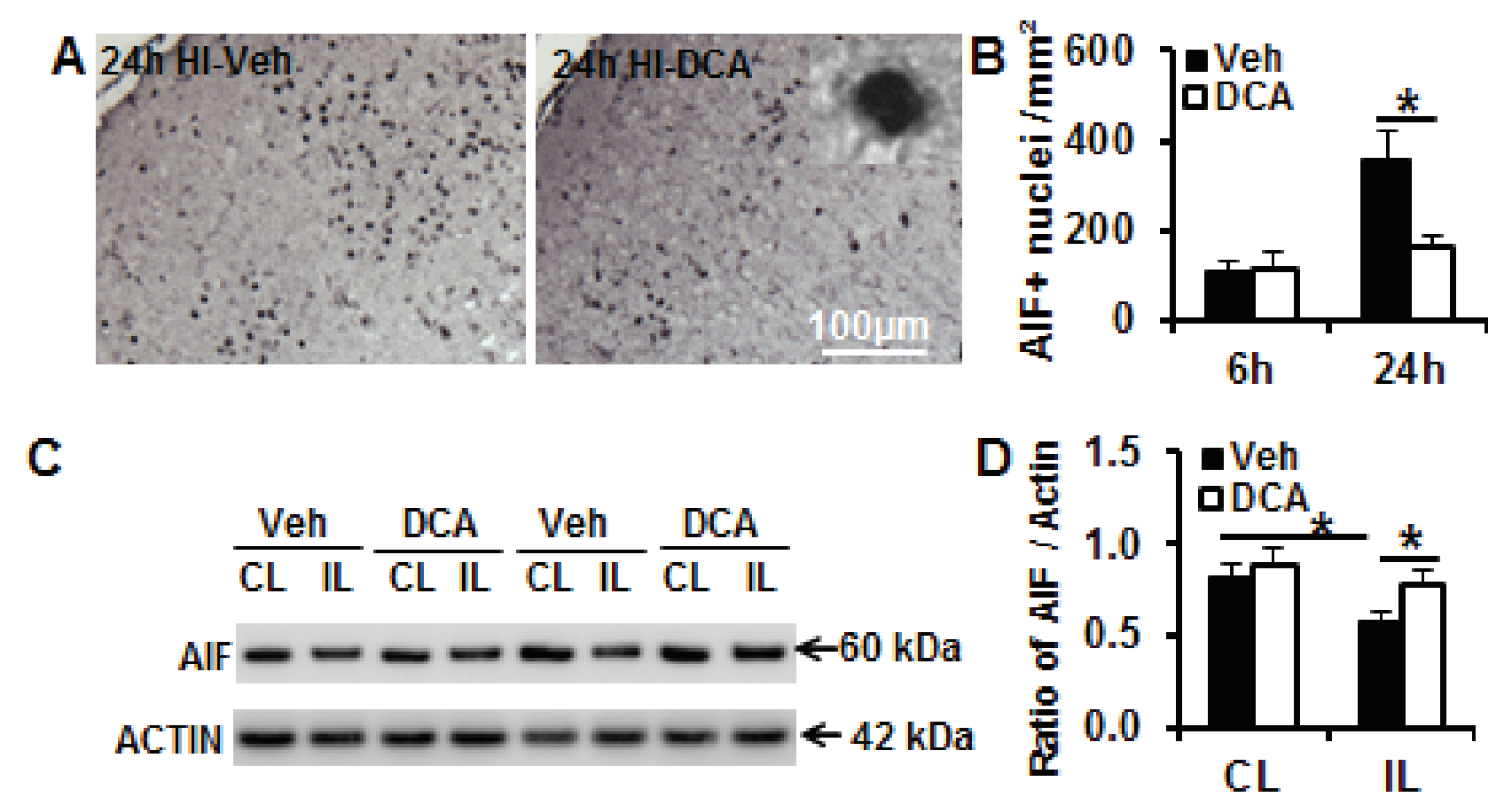

Figure 6: DCA treatment reduced AIF nuclear translocation in the mouse brain after HI. A. Representative AIF staining in the cortex at $24 \mathrm{~h}$ after HI. B. AIF-positive nuclei were reduced in the border zone of the cortical infarction in the DCA-treated group and the vehicle-treated group at $24 \mathrm{~h}$ after HI ( $n=8$ for the vehicle group, $n=7$ for the DCA group). C. Representative pictures show immunoblotting of the mouse brain mitochondrial fraction at $24 \mathrm{~h}$ after $\mathrm{HI}$ from the contralateral hemisphere (CL) and ipsilateral hemisphere (IL) in both vehicle (Veh) and DCA treatment groups. D. Quantification of AIF immunoblotting normalized to actin in the vehicle treatment group and DCA treatment group. $\mathrm{n}=7$ for the vehicle group and $n=6$ for the DCA group. ${ }^{*} p<0.05$. 
The tricarboxylic acid cycle is a series of chemical reactions that take place in mitochondria to generate energy in the form of ATP. As part of this cycle, PDH mediates AcCoA formation from pyruvate, which feeds the electron transport chain responsible for ATP synthesis and oxygen consumption. Phosphorylation of PDH by PDK inactivates $\mathrm{PDH}$, and this promotes pyruvate conversion to lactate instead of AcCoA in glycolysis and thus limits the entry of pyruvate into the mitochondria. DCA inhibits PDK, and this means that most of the PDH will be in the active form and thus pyruvate will move into the mitochondria for conversion to $\mathrm{AcCoA}$ and the subsequent generation of citrate and ATP. HI insult induces mitochondrial impairment as well as primary and secondary phases of energy failure and cell death [30]. In the present study, we found that DCA treatment immediately after HI increased AcCoA and reduced neuronal cell death and brain injury. Thus the neuroprotective effect of DCA might be at least in part related to increased PDH activity, which increases the cerebral metabolic rate after the HI insult.

Mitochondrial biogenesis as part of normal cellular respiration, and mitochondrial fusion and fission for maintenance of organelle function, are crucial for functional recovery of neurons after injury, and this is a highly regulated process that requires the participation of both the nuclear and mitochondrial genomes [31]. Cerebral insults cause mitochondrial dysfunction, which is reflected by mtDNA damage and changes in mtDNA content, as well as changes in the transcription of mitochondrial genes and nuclear genes encoding mitochondrial proteins, changes in protein synthesis, and changes in mitochondrial function. $P G C-1 \alpha$ serves as a key regulator of energy metabolism, and it can co-activate numerous metabolically relevant nuclear and non-nuclear receptor transcription factors such as Nrf-1 and Tfam [32]. DCA treatment increased mitochondrial biogenesis-related $P g c-1 \alpha$ mRNA at $6 \mathrm{~h}$ and $\mathrm{Nrf}-1 \mathrm{mRNA}$ at $24 \mathrm{~h}$ after HI, but not Tfam mRNA. The different expression profiles of these genes might be related to different temporal changes after HI $[32,33]$. Even though one of the mitochondria-specific proteins increased at $24 \mathrm{~h}$ after HI with DCA treatment, there was no change in mtDNA copy number in the normal controls at either $6 \mathrm{~h}$ or $24 \mathrm{~h}$ after HI. Furthermore, DCA treatment had no effect on mitochondria-specific proteins in the normal controls. These results suggest that DCA treatment alters some of the mitochondrial biogenesisrelated genes, but it appears to have no significant effect on mitochondrial biogenesis in the neonatal mouse brain after HI.

Mitochondria are highly dynamic organelles that undergo permanent fusion and fission, an antagonistic process that links mitochondrial dynamics to the balance
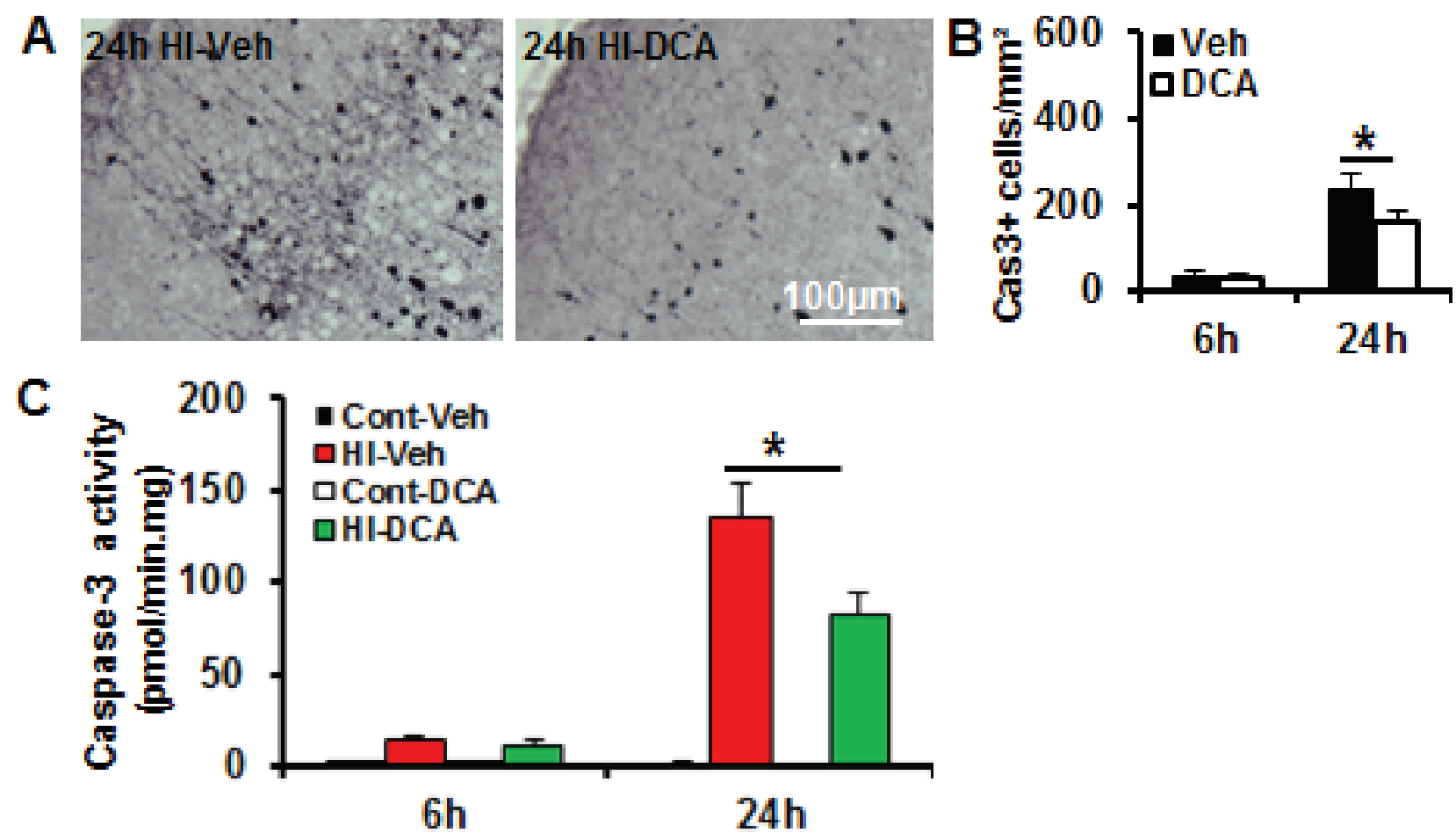

Figure 7: DCA treatment decreased caspase-3 activation in the mouse brain after HI. A. Representative pictures show staining for the active form of caspase-3 in the brain cortex at $24 \mathrm{~h}$ after HI. B. Quantification of the caspase-3-positive cells in the IHC in the cortex. C. The caspase-3 activity (as indicated by DEVD cleavage) was assayed in the brain cortical homogenate at $6 \mathrm{~h}$ and $24 \mathrm{~h}$ after $\mathrm{HI}$ in the DCA-treated mice $(n=7)$ and the vehicle-treated mice $(n=8) .{ }^{*} p<0.05$. 
between energy demand and nutrient supply [34] and is important for mitochondrial function and cellular survival [35]. Highly fused mitochondria are formed under nutrient deprivation to optimize mitochondrial function and to maximize ATP synthesis. In the pathological condition of HI, maintaining mitochondrial fusion might have a protective effect. In contrast, mitochondrial fission is activated under conditions of excess nutrients [36]. In the current study, HI insult decreased the expression of the mitochondrial fusion gene Opal, and there was a concomitant decrease in expression and increase in cleavage of the OPA1 protein. These data suggest that $\mathrm{HI}$ insult induces a reduction in mitochondrial fusion. Because phosphorylation at Ser637 of DRP1 inhibits mitochondrial fission, the downregulation of P-DRP1 observed after $\mathrm{HI}$ insult indicates that $\mathrm{HI}$ insult leads to increased mitochondrial fission. These data are consistent with previous reports that ischemia reperfusion induces an increase of mitochondrial fission [37-39]. However, even though DCA treatment altered mitochondrial fusion and fission-related genes, it did not affect the expression of P-DRP1 or cleavage of OPA1. These results suggest that neuroprotection by DCA treatment in the current study was not related to mitochondrial fusion or fission.

Autophagy is an important physiological mechanism to maintain cellular homeostasis and survival, and the immature brain retains its autophagic machinery to a greater extent than the adult brain [26] as part of normal brain development $[40,41]$. Thus, basal autophagy plays an essential role in cell survival under physiological conditions. However, increased autophagy can be activated by many forms of stress such as starvation and ischemic insult [42-44]. Starvation or nutrient depletion results in the depletion of intracellular AcCoA, which is one of the physiological triggers of autophagy to recycle amino acids and fatty acids to produce energy and remove damaged organelles. In the immature brain, energy failure is induced rapidly after HI [11], and autophagy activity - as indicated by the autophagosome-related marker LC3-II - increases [26]. Inhibition of autophagy provides neuroprotection $[24,45]$. These results indicate that autophagy could be considered a potential therapeutic target for the treatment of perinatal HI brain injury. In this study, DCA administration increased AcCoA production and reduced autophagy activity - as indicated by the sustained levels of SQSTM1 - and these effects might at least partly contribute to neuroprotection.

Apoptosis plays a more prominent role in the immature brain [26], and this includes both caspasedependent and -independent pathways, and combined inhibition of both pathways provides synergistic protection against neonatal HI brain injury [46]. DCA treatment inhibits mitochondrial release of AIF, and although the precise mechanism is not clear, this process appears to be related to improved mitochondrial energy metabolism and reduced mitochondrial membrane permeability at early stages after the injury. This reduced permeability leads to a reduction in the amount of pro-apoptotic proteins, such as AIF and cytochrome c, that are released from the mitochondrial intermembrane space after the insult. Cytochrome c release from the mitochondria into the cytosol leads to activation of procaspase-9, which in turn cleaves and activates procaspase-3 [47] and leads to apoptosis. These data suggest that DCA-mediated neuroprotection in the neonatal mice might involve multiple anti-apoptotic mechanisms.

DCA as an orphan drug has been used for decades to treat children with inborn errors of mitochondrial metabolism, and it has been shown to have beneficial effects $[17,19]$ with higher doses being more effective [48]. DCA is neuroprotective at a dose of $100 \mathrm{mg} / \mathrm{kg}$, but not at a lower dose of $10 \mathrm{mg} / \mathrm{kg}$ [28, 29]. Long-term DCA administration is considered generally safe and well tolerated in pediatric patients [19, 20]. It has been reported that daily DCA treatment at $25 \mathrm{mg} / \mathrm{kg}$ is associated with reversible neuropathy toxicity [49], but it cannot be determined whether this is attributed to DCA or to progression of underlying disease [20]. This inconsistency might be related to different conditions in the patients. In neonatal HI with an acute mitochondrial metabolic disturbance, DCA treatment improves mitochondrial metabolism over the short term, which is different from hereditary defects in mitochondrial metabolism that require long-term treatment.

In summary, post-ischemic DCA treatment reduces both gray-matter and white-matter injury in neonatal mice after HI insult. DCA treatment could therefore be a useful therapeutic strategy to improve neurological outcomes in perinatal asphyxia-induced brain injury.

\section{MATERIALS AND METHODS}

\section{Cerebral hypoxia-ischemia}

PND 9 C57BL/6J male mouse pups were purchased from Charles River (Germany) and housed with their dams in a temperature-controlled and pathogen-free environment with a 12:12-hour light-dark cycle [50,51]. The pups were randomly assigned to DCA or phosphatebuffered saline (PBS) treatment groups. The pups were anesthetized with isoflurane (5\% for induction, 1.5-2.0\% for maintenance) in a mixture of nitrous oxide and oxygen $(1: 1)$. The left common carotid artery was isolated and cut between double ligatures of prolene sutures (6.0). The duration of anesthesia was less than $5 \mathrm{~min}$. After the surgical procedures, the wounds were infiltrated with lidocaine for analgesia, and the pups were returned to their cages with the dams and allowed to recover for 1 hour. The pups were then placed in an incubator perfused with a humidified gas mixture $(10 \% \pm 0.01 \%$ oxygen in nitrogen $)$ 
at $36^{\circ} \mathrm{C}$ for 40 minutes to induce a mild to moderate brain injury. After HI, the pups were returned to their dams until they were sacrificed. Control pups were not subjected to ligation or hypoxia. All animal experiments were approved by the Animal Ethical Committee of the University of Gothenburg (112/2014).

\section{DCA administration}

The DCA (10 mg/mL dissolved in PBS, DCA-lab, Lithuania, 2156-56-1) was prepared freshly prior to use and injected intraperitoneally at a dose of $100 \mathrm{mg} / \mathrm{kg}$ immediately after HI. Two additional injections (100 mg/ $\mathrm{kg}$ ) were administered at 24-hour intervals, and the pups were sacrificed at $72 \mathrm{~h}$ after HI. Control pups received an equivalent volume of PBS.

\section{Immunohistochemistry staining}

At $6 \mathrm{~h}, 24 \mathrm{~h}$, and $72 \mathrm{~h}$ after HI-induced injury, the pups were deeply anesthetized with $50 \mathrm{mg} / \mathrm{ml}$ phenobarbital and perfused intracardially with PBS and 5\% buffered formaldehyde (Histofix; Histolab, Gothenburg, Sweden). Brains were removed and fixed in $5 \%$ buffered formaldehyde at $4^{\circ} \mathrm{C}$ for $18-24 \mathrm{~h}$. After dehydration with graded ethanol and xylene, the brains were paraffin-embedded and cut into $5 \mu \mathrm{m}$ coronal sections. Every 100th section throughout the whole brain for microtubule-associated protein 2 (MAP2) staining and myelin basic protein $(\mathrm{MBP})$ staining $(\mathrm{DCA}=25$, vehicle $=24,72 \mathrm{~h}$ ), and every 50th section in the hippocampus for caspase 3 staining $(\mathrm{DCA}=7$, vehicle $=8,24 \mathrm{~h}$ ), were deparaffinized in xylene and rehydrated in graded ethanol concentrations. Antigen retrieval was performed by heating the sections in $10 \mathrm{mM}$ boiling sodium citrate buffer ( $\mathrm{pH}$ 6.0) for $10 \mathrm{~min}$. Nonspecific binding was blocked for $30 \mathrm{~min}$ with $4 \%$ donkey or goat serum in PBS for $30 \mathrm{~min}$. The primary antibodies were monoclonal mouse anti-MAP2 (1:1000 dilution, clone HM-2, Sigma, M9942), rabbit anti-MBP (1:10,000 dilution, Sternberger Monoclonal Incorporated, SMI 94), rabbit anti-active caspase-3 (1:150 dilution, BD Pharmingen, 559565), and goat anti-AIF (1:100 dilution, $2 \mu \mathrm{g} / \mathrm{ml}$, Santa Cruz Biotechnologies, sc-9416). After incubating the sections with the primary antibodies at $20^{\circ} \mathrm{C}$ for $60 \mathrm{~min}$ or overnight at $4^{\circ} \mathrm{C}$, the appropriate biotinylated secondary antibodies (1:200 dilution; all from Vector Laboratories, Burlingame, CA, USA) were added for $60 \mathrm{~min}$ at room temperature. After blocking endogenous peroxidase activity with $3 \% \mathrm{H}_{2} \mathrm{O}_{2}$ for $10 \mathrm{~min}$, the sections were visualized with Vectastain ABC Elite (Vector Laboratories) and $0.5 \mathrm{mg} / \mathrm{mL} \mathrm{3,3,9-diaminobenzidine} \mathrm{enhanced} \mathrm{with}$ ammonium nickel sulfate, beta-D glucose, ammonium chloride, and beta-glucose oxidase. After dehydrating with graded ethanol and xylene, the sections were mounted using Vector mounting medium.

\section{Cell counting}

Area contours were drawn and measured in every $50^{\text {th }}$ section. The active caspase- 3 and AIF-positive cells $(\mathrm{DCA}=7$, vehicle $=8,24 \mathrm{~h})$ were counted at $400 \times$ magnification in the border zone of the injured cortex within an area of $0.196 \mathrm{~mm}^{2}$ (one visual field) using Micro Image (Olympus, Japan). Three sections were counted from each brain with an interval of $250 \mu \mathrm{m}$. The average was defined as $n=1$ when comparing different brains. All of the counting was carried out by investigators blinded to group assignment.

\section{Brain injury evaluation}

The gray-matter area was determined by measuring the MAP2 immunoreactive area from eight serial sections per animal. Brain injury was evaluated by the volume of infarction and total hemispheric tissue loss, and neuropathological scoring was performed by a person who did not have prior knowledge of the groups. The cerebral subcortical white matter area was determined by measuring the MBP immunoreactive area in five serial sections per animal. The MAP2 or MBP-positive and -negative areas in each section were measured in both hemispheres using Micro Image (Olympus, Japan). The tissue volume was calculated from the MAP2 or MBPpositive or -negative areas according to the Cavalieri principle using the following formula: $\mathrm{V}=\Sigma \mathrm{A} \times \mathrm{P} \times$ $\mathrm{T}$, where $\mathrm{V}=$ the total volume, $\Sigma \mathrm{A}=$ the sum of area measurements, $\mathrm{P}=$ the inverse of the sampling fraction, and $\mathrm{T}=$ the section thickness. The total hemispheric tissue loss was calculated as the MAP2-positive volume in the contralateral hemisphere minus the MAP2-positive volume in the ipsilateral hemisphere. The MBP-positive area was measured in each hemisphere, and the total MBP tissue loss ratio was calculated as: ((contralateral hemisphere - ipsilateral hemisphere) / contralateral hemisphere) $\times 100 \%$. The neuropathological score of gray matter from different brain regions was assessed. Briefly, the cortical injury was graded from 0 to 4 with 0 being no observable injury and 4 indicating confluent infarction. The injury in the hippocampus, striatum, and thalamus was assessed both with respect to hypotrophy (scored from 0 to 3 ) and injury/infarction (scored from 0 to 3 ), resulting in a total possible score of 22 .

\section{Sample preparation for Western blot, caspase activity, and ELISA kits}

The pups were sacrificed by decapitation at $6 \mathrm{~h}$ or $24 \mathrm{~h}$ after HI. Tissue from the parietal cortex (including 
the hippocampus) in each hemisphere was rapidly dissected out on a bed of ice. Tissue samples were homogenized immediately using a 2-mL glass/glass homogenizer (Merck Eurolab, Gothenburg, Sweden) on ice, and isolation buffer was added (15 mM Tris- $\mathrm{HCl}$ (pH 7.6), $320 \mathrm{mM}$ sucrose, $1 \mathrm{mM}$ dithiothreitol, $3 \mathrm{mM}$ EDTA-K, and $0.5 \%$ protease inhibitor cocktail, which was added fresh immediately prior to use). Half of the homogenates were aliquoted and stored at $-80^{\circ} \mathrm{C}$, and the other half were centrifuged at $800 \times g$ at $4^{\circ} \mathrm{C}$ for $10 \mathrm{~min}$. The pellet fraction was washed, recentrifuged, and saved as the nuclear fraction. The supernatants were further centrifuged at $9200 \times g$ for $15 \mathrm{~min}$ at $4^{\circ} \mathrm{C}$, producing mitochondrial and synaptosomal fractions in the pellet and crude cytosolic fractions in the supernatants. The enriched mitochondrial fraction was washed and centrifuged. All fractions were stored at $-80^{\circ} \mathrm{C}$.

\section{Immunoblotting}

Protein concentration was determined using the bicinchoninic acid method. Samples with a volume of $65 \mu \mathrm{L}$ were mixed with $25 \mu \mathrm{l}$ NuPAGE LDS $4 \times$ sample buffer (ThermoFisher Scientific, NP0007) and $10 \mu \mathrm{l}$ reducing agent (ThermoFisher Scientific, NP0004) and heated at $70^{\circ} \mathrm{C}$ for $10 \mathrm{~min}$. Individual samples of 10 $\mu \mathrm{g}$ protein were loaded and run on $4 \%-12 \%$ NuPAGE Bis-Tris gels (Novex) and transferred to reinforced nitrocellulose membranes. After blocking with $30 \mathrm{mM}$ Tris- $\mathrm{HCl}$ (pH 7.5), $100 \mathrm{mM} \mathrm{NaCl}$, and $0.1 \%$ Tween 20 containing $5 \%$ fat-free milk powder for $60 \mathrm{~min}$ at room temperature, the membranes were incubated with the following primary antibodies: rabbit anti-Actin (1:200 dilution, Sigma, A2066), goat anti-AIF (1:1000 dilution, Santa Cruz Biotechnologies, sc-9416), rabbit anti-LC3 (1:1000 dilution, Cell Signaling, 2775), and rabbit antiSQSTM1 (1:1000 dilution, Enzo Life Science, PW9860), rabbit anti-phospho-DRP1 (Ser637) (1:1000 dilution, Cell Signaling, 4867); mouse anti-OPA1 (1:1000 dilution, BD bioscience, 612606), at room temperature for $60 \mathrm{~min}$. After washing, the membranes were incubated with a peroxidase-labeled secondary antibody for $30 \mathrm{~min}$ at room temperature (goat anti-rabbit (1:2,000 dilution), horse anti-goat (1:2,000 dilution), or horse anti-mouse (1:4,000 dilution)). Immunoreactive species were visualized using the Super Signal West Dura substrate (ThermoFisher Scientific, 34075) and an LAS 3000 cooled CCD camera (Fujifilm, Japan). Actin was used as the loading control.

\section{Caspase-3 activity assay}

Protein concentration was determined using the bicinchoninic acid method. For the caspase-3 activity assay, samples of $25 \mu \mathrm{l}$ homogenate were mixed with 75 $\mu \mathrm{l}$ extraction buffer containing $50 \mathrm{mM}$ Tris- $\mathrm{HCl}(\mathrm{pH} 7.3)$,
$100 \mathrm{mM} \mathrm{NaCl}, 5$ mM EDTA, 1 mM EGTA, 1 mM PMSF, and $1 \%$ protease inhibitor cocktail on a microtiter plate. After incubation for $15 \mathrm{~min}$ at room temperature, $25 \mu \mathrm{M}$ Caspase-3-substrate (DEVD) in $100 \mu$ extraction buffer, without protease inhibitors or CHAPS but with $4 \mathrm{mM}$ DTT, was added. Caspase-3 activity was measured using a Spectramax Gemini microplate fluorometer (excitation/ emission wavelength 380/460 $\mathrm{nm}$ every $2 \mathrm{~min}$ for $2 \mathrm{~h}$ at $37^{\circ} \mathrm{C}$ ) and expressed as pmol AMC released $/ \mathrm{mg}$ protein per minute.

\section{PDH assay}

The samples of enriched mitochondrial fraction were used for PDH (Biovision, Milpitas, K679-199) activity measurement according to the manufacturer's instructions. Briefly, $5 \mu 1$ enriched mitochondrial fraction was mixed with $45 \mu \mathrm{PDH}$ assay buffer and $50 \mu 1$ reaction mix, and the absorbance was measured immediately at 450 $\mathrm{nm}$ in kinetic mode for $60 \mathrm{~min}$ at $37^{\circ} \mathrm{C}$. The activity was calculated according to the standard curve and expressed as $\mathrm{mU} / \mathrm{mg}$ protein.

\section{Acetyl-coenzyme A assay}

AcCoA was measured in the mitochondrial fraction by using an assay kit (Sigma-Aldrich, MAK039) according to the manufacturer's instructions. Briefly, 40 $\mu \mathrm{l}$ sample was mixed with $20 \mu \mathrm{l} 1 \mathrm{~N}$ perchloric acid and centrifuged at $13,000 \times \mathrm{g}$ at $4^{\circ} \mathrm{C}$ for $10 \mathrm{~min}$ to remove insoluble material. The supernatant was neutralized with $3 \mathrm{M}$ potassium bicarbonate solution at $\mathrm{pH} 6.8$ and spun down to pellet the potassium bicarbonate. The supernatant sample $(20 \mu \mathrm{l})$ was mixed with $30 \mu \mathrm{l}$ AcCoA assay buffer in a 96 well plate and then $10 \mu \mathrm{AcCoA}$ quencher was added and incubated for $5 \mathrm{~min}$ at room temperature. Finally, $2 \mu$ quench remover was added to each sample well and incubated for an additional 5 min. After adding $50 \mu \mathrm{l}$ of the reaction mix to each well and incubating the reaction for $10 \mathrm{~min}$ at $37^{\circ} \mathrm{C}$, the AcCoA concentration was measured in a Spectramax Gemini microplate fluorometer (with an excitation wavelength of $535 \mathrm{~nm}$ and an emission wavelength of $587 \mathrm{~nm}$ ) and expressed as $\mathrm{pmol} / \mathrm{mg}$ protein.

\section{Lactate assay}

The lactate concentrations in the cortex homogenate samples at $24 \mathrm{~h}$ after HI were measured using the Lactate Colorimetric Assay Kit (Biovision, Milpitas, K607-100) according to the manufacturer's instructions. Briefly, samples of homogenate $(25 \mu \mathrm{l})$ were mixed with $25 \mu \mathrm{l}$ assay buffer on a microtiter plate and then $50 \mu \mathrm{l}$ reaction mixtures containing $46 \mu \mathrm{l}$ lactate assay buffer, $2 \mu \mathrm{l}$ lactate enzyme mix, and $2 \mu \mathrm{l}$ probe were added. After 
incubation for $30 \mathrm{~min}$ at room temperature, the lactate concentration was measured with a Spectramax Gemini microplate reader based on the absorbance (OD $570 \mathrm{~nm}$ ) and expressed as nmol/mg protein.

\section{Mitochondrial DNA copy number measurement}

Total DNA from the cortex was isolated using a genomic DNA isolation kit (DNeasy Blood \& Tissue Kit, Qiagen). The amount of mitochondrial DNA relative to nuclear genomic DNA was determined by quantitative real-time PCR. The two nuclear genes were Ywhaz (sense: 5'-GAG GAA GAA TCG TGA GTT AGT T-3', anti-sense: 5'-TGG TGA TGG TTG AGA CAG A-3') and $36 B 4$ (sense: 5'-GTT GTT AGC CTG TGA TAG CA-3', antisense: 5'-CCGACCAGCAATGTTCTATT-3'), and the two mitochondrial genes were ND4 (sense: 5'-CCT CAG TTA GCC ACA TAG C-3', anti-sense: 5'- GAT TCG TTC GTA GTT GGA GTT-3') and D-loop (sense: 5'-GCC CAT GAC CAA CAT AAC TG-3', anti-sense: 5'-CCT TGA CGG CTA TGT TGA TG-3'). The relative mitochondrial DNA level was calculated based on the threshold cycle $(\mathrm{Ct})$ as $2-\Delta(\Delta \mathrm{Ct})$.

\section{Mitochondria biogenesis, fission, and fusion gene mRNA expression}

Total RNA was isolated with an RNA isolation kit (RNeasy Mini Kit, Qiagen, 74104) according to the manufacturer's instructions. The concentration and purity of all RNA samples were determined using a Nanodrop spectrophotometer (Nanodrop Technologies). The integrity of the RNA was measured using an Experion RNA StdSens Analysis kit (Bio-Rad) on an Automated Electrophoresis Station machine (Bio-Rad). One microgram of total RNA was reverse transcribed using the QuantiTect Reverse Transcription kit (Qiagen, 205311). Quantitative real time PCR was performed using the LightCycler 480 instrument (Roche Diagnostics, Germany) and the SYBR Green technique according to the manufacturer's instructions. The primers used in the qRT-PCR reactions were designed by Beacon Designer software (free trial, PREMIER Biosoft) and included the mitochondrial biogenesis genes $P g c-1 \alpha$ (sense: 5'-CCA GGT CAA GAT CAA GGT-3', antisense: 5'-CGT GCT CAT AGG CTT CAT A-3'), Tfam (sense: 5'-ACC TCG TTC AGC ATA TAA CAT T-3', anti-sense: 5'-ATC ACT TCG TCC AAC TTC AG-3'), and Nrfl (sense: 5'-CCA CAG GAG GTT AAT TCA GAG-3', antisense: 5'-ACA TCA CTG CGG ACA TTG-3') and the mitochondrial fission and fusion genes Drpl (sense: 5'-TGC TCA GTA TCA GTC TCT TC-3', antisense: 5'-GGT TCC TTC AAT CGT GTT AC-3'), Mfnl (sense: 5'-CAC TGA TGA ACA CGG AGA A-3', antisense: 5'-CGA CGG ACT TAC AAC CTT-3'), Opal (sense: 5'-CCT GTG AAG TCT
GCC AAT-3', antisense: 5'-TTA GAG AAG AGA ACT GCT GAA AT-3'). The reference genes Ywhaz (sense: 5'CCT CAA CTT CTC TGT GTT CTA TT -3', antisense: 5'-ACG ACT CTT CAC TTA ATG TAT CAA-3'), Sdha (sense: 5'-TTG CCT TGC CAG GAC TTA-3', antisense: 5'-CAC CTT GAC TGT TGA TGA GAA T-3') [52]. The relative expression levels of mRNAs were calculated by the method of geometric averaging of multiple internal control genes.

\section{Statistical analysis}

The Statistical Package for the Social Sciences 21.0 (SPSS, IBM, NY, USA) was used for all analyses. Comparisons between groups were performed by Student's $t$-test, and data with unequal variance were compared with the Mann-Whitney $U$-test. Two-way ANOVA followed by a Bonferroni post hoc test was used for multiple comparison correction of data from more than two groups. Results are presented as means \pm standard errors of the mean (SEM). $p<0.05$ was considered statistically significant.

\section{CONFLICTS OF INTEREST}

The authors have declared that no conflict of interest exists.

\section{GRANT SUPPORT}

This work was supported by the National Nature Science Foundation of China (31271152 to CZ), the Chinese Scholarship Council (YS), the Department of Science and Technology (134200510023 to CZ), the Department of Health of Henan Province(201201002 to CZ), Science and Technology Bureau of Zhengzhou(131PCXTD621 to CZ), the Swedish Research Council (2015-02845 to CZ, 2013-2475 to XW), the Swedish Childhood Cancer Foundation (2013/0027 to CZ), The Swedish Cancer Foundation (2014/707 to CZ), Swedish governmental grants to scientists working in health care (ALFGBG-429271 to CZ, ALFGBG-367051 to XW), VINNMER-Marie Curie international qualification (VINNOVA, 2011-03458 to XW, 2015-04780 to CZ), the Wilhelm and Martina Lundgren Foundation, and the Gothenburg Medical Society.

\section{REFERENCES}

1. Black RE, Cousens S, Johnson HL, Lawn JE, Rudan I, Bassani DG, Jha P, Campbell H, Walker CF, Cibulskis R, Eisele T, Liu L, Mathers C. Global, regional, and national causes of child mortality in 2008: a systematic analysis. Lancet. 2010;375:1969-1987.

2. Liu L, Oza S, Hogan D, Perin J, Rudan I, Lawn JE, Cousens 
S, Mathers C and Black RE. Global, regional, and national causes of child mortality in $2000-13$, with projections to inform post-2015 priorities: an updated systematic analysis. Lancet. 2015;385:430-440.

3. Douglas-Escobar M, Weiss MD. Hypoxic-ischemic encephalopathy: a review for the clinician. JAMA Pediatr. 2015;169:397-403.

4. Hagberg H, Mallard C, Rousset CI, Thornton C. Mitochondria: hub of injury responses in the developing brain. Lancet Neurol. 2014;13:217-232.

5. Rousset CI, Baburamani AA, Thornton C, Hagberg H. Mitochondria and perinatal brain injury. J Matern Fetal Neonatal Med. 2012;25 Suppl 1:35-38.

6. Azzopardi D, Strohm B, Marlow N, Brocklehurst P, Deierl A, Eddama O, Goodwin J, Halliday HL, Juszczak E, Kapellou O, Levene M, Linsell L, Omar O, et al. Effects of hypothermia for perinatal asphyxia on childhood outcomes. N Engl J Med. 2014;371:140-149.

7. Zhou WH, Cheng GQ, Shao XM, Liu XZ, Shan RB, Zhuang DY, Zhou CL, Du LZ, Cao Y, Yang Q, Wang LS. Selective head cooling with mild systemic hypothermia after neonatal hypoxic-ischemic encephalopathy: a multicenter randomized controlled trial in China. J Pediatr. 2010;157:367-372.

8. Zhu C, Kang W, Xu F, Cheng X, Zhang Z, Jia L, Ji L, Guo X, Xiong H, Simbruner G, Blomgren K and Wang X. Erythropoietin improved neurologic outcomes in newborns with hypoxic-ischemic encephalopathy. Pediatrics. 2009;124(2):e218-26.

9. $\mathrm{Wu}$ YW, Bauer LA, Ballard RA, Ferriero DM, Glidden DV, Mayock DE, Chang T, Durand DJ, Song D, Bonifacio SL, Gonzalez FF, Glass HC and Juul SE. Erythropoietin for neuroprotection in neonatal encephalopathy: safety and pharmacokinetics. Pediatrics. 2012;130:683-691.

10. Johnston MV, Fatemi A, Wilson MA, Northington F. Treatment advances in neonatal neuroprotection and neurointensive care. Lancet Neurol. 2011;10:372-382.

11. Yager JY, Brucklacher RM, Vannucci RC. Cerebral energy metabolism during hypoxia-ischemia and early recovery in immature rats. Am J Physiol. 1992;262:H672-677.

12. Blomgren $\mathrm{K}$, Zhu $\mathrm{C}$, Wang $\mathrm{X}$, Karlsson JO, Leverin $\mathrm{AL}$, Bahr BA, Mallard C and Hagberg H. Synergistic activation of caspase- 3 by m-calpain after neonatal hypoxia-ischemia: a mechanism of "pathological apoptosis"? J Biol Chem. 2001;276:10191-10198.

13. Marino G, Pietrocola F, Eisenberg T, Kong Y, Malik SA, Andryushkova A, Schroeder S, Pendl T, Harger A, NisoSantano M, Zamzami N, Scoazec M, Durand S, et al. Regulation of autophagy by cytosolic acetyl-coenzyme A. Mol Cell. 2014;53:710-725.

14. Murray DM, Boylan GB, Fitzgerald AP, Ryan CA, Murphy BP, Connolly S. Persistent lactic acidosis in neonatal hypoxic-ischaemic encephalopathy correlates with EEG grade and electrographic seizure burden. Arch Dis Child Fetal Neonatal Ed. 2008;93:F183-186.

15. Williams PJ, Lane JR, Turkel CC, Capparelli EV, Dziewanowska Z, Fox AW. Dichloroacetate: population pharmacokinetics with a pharmacodynamic sequential link model. J Clin Pharmacol. 2001;41:259-267.

16. Berendzen K, Theriaque DW, Shuster J, Stacpoole PW. Therapeutic potential of dichloroacetate for pyruvate dehydrogenase complex deficiency. Mitochondrion. 2006;6:126-135.

17. Koga Y, Povalko N, Katayama K, Kakimoto N, Matsuishi T, Naito E and Tanaka M. Beneficial effect of pyruvate therapy on Leigh syndrome due to a novel mutation in PDH E1alpha gene. Brain Dev. 2012;34:87-91.

18. Stacpoole PW, Kerr DS, Barnes C, Bunch ST, Carney PR, Fennell EM, Felitsyn NM, Gilmore RL, Greer M, Henderson GN, Hutson AD, Neiberger RE, O'Brien RG, et al. Controlled clinical trial of dichloroacetate for treatment of congenital lactic acidosis in children. Pediatrics. 2006;117:1519-1531

19. Abdelmalak M, Lew A, Ramezani R, Shroads AL, Coats BS, Langaee T, Shankar MN, Neiberger RE, Subramony SH and Stacpoole PW. Long-term safety of dichloroacetate in congenital lactic acidosis. Mol Genet Metab. 2013;109:139143.

20. Stacpoole PW, Gilbert LR, Neiberger RE, Carney PR, Valenstein E, Theriaque DW and Shuster JJ. Evaluation of long-term treatment of children with congenital lactic acidosis with dichloroacetate. Pediatrics. 2008;121:e1223228.

21. Katayama Y, Welsh FA. Effect of dichloroacetate on regional energy metabolites and pyruvate dehydrogenase activity during ischemia and reperfusion in gerbil brain. $\mathrm{J}$ Neurochem. 1989;52:1817-1822.

22. Corbett R, Laptook A, Gee J, Garcia D, Silmon S, Tollefsbol G. Age-related differences in the effect of dichloroacetate on postischemic lactate and acid clearance measured in vivo using magnetic resonance spectroscopy and microdialysis. J Neurochem. 1998;71:1205-1214.

23. Madeo F, Pietrocola F, Eisenberg T, Kroemer G. Caloric restriction mimetics: towards a molecular definition. Nat Rev Drug Discov. 2014;13:727-740.

24. Ginet V, Spiehlmann A, Rummel C, Rudinskiy N, Grishchuk Y, Luthi-Carter R, Clarke PG, Truttmann $\mathrm{AC}$ and Puyal J. Involvement of autophagy in hypoxicexcitotoxic neuronal death. Autophagy. 2014;10:846-860.

25. Xie C, Ginet V, Sun Y, Koike M, Zhou K, Li T, Li H, Li Q, Wang X, Yasuo U, Truttmann A, Kroemer G, Puyal $\mathrm{J}$, et al. Neuroprotection by selective neuronal deletion of autophagy-related gene 7 in neonatal brain injury. Autophagy. 2016; 12:410-423.

26. Zhu C, Wang X, Xu F, Bahr BA, Shibata M, Uchiyama $\mathrm{Y}$, Hagberg $\mathrm{H}$ and Blomgren $\mathrm{K}$. The influence of age on 
apoptotic and other mechanisms of cell death after cerebral hypoxia-ischemia. Cell Death Differ. 2005;12:162-176.

27. Wang $\mathrm{X}$, Karlsson JO, Zhu C, Bahr BA, Hagberg H, Blomgren K. Caspase-3 activation after neonatal rat cerebral hypoxia-ischemia. Biol Neonate. 2001;79:172-179.

28. Chang LH, Shimizu H, Abiko H, Swanson RA, Faden AI, James TL and Weinstein PR. Effect of dichloroacetate on recovery of brain lactate, phosphorus energy metabolites, and glutamate during reperfusion after complete cerebral ischemia in rats. J Cereb Blood Flow Metab. 1992;12:10301038.

29. Peeling J, Sutherland G, Brown RA, Curry S. Protective effect of dichloroacetate in a rat model of forebrain ischemia. Neurosci Lett. 1996;208:21-24.

30. Iwata O, Iwata S, Bainbridge A, De Vita E, Matsuishi T, Cady EB and Robertson NJ. Supra- and sub-baseline phosphocreatine recovery in developing brain after transient hypoxia-ischaemia: relation to baseline energetics, insult severity and outcome. Brain. 2008;131:2220-2226.

31. Medeiros DM. Assessing mitochondria biogenesis. Methods. 2008;46:288-294.

32. Yin W, Signore AP, Iwai M, Cao G, Gao Y, Chen J. Rapidly increased neuronal mitochondrial biogenesis after hypoxic-ischemic brain injury. Stroke. 2008;39:3057-3063.

33. Correa F, Ljunggren E, Patil J, Wang X, Hagberg H, Mallard C, Sandberg M. Time-dependent effects of systemic lipopolysaccharide injection on regulators of antioxidant defence Nrf2 and PGC-1alpha in the neonatal rat brain. Neuroimmunomodulation. 2013;20:185-193.

34. Liesa M, Shirihai OS. Mitochondrial dynamics in the regulation of nutrient utilization and energy expenditure. Cell Metab. 2013;17:491-506.

35. Sheridan C, Martin SJ. Mitochondrial fission/fusion dynamics and apoptosis. Mitochondrion. 2010;10:640-648.

36. Twig G, Elorza A, Molina AJ, Mohamed H, Wikstrom JD, Walzer G, Stiles L, Haigh SE, Katz S, Las G, Alroy $\mathrm{J}, \mathrm{Wu} \mathrm{M}, \mathrm{Py} \mathrm{BF}$, et al. Fission and selective fusion govern mitochondrial segregation and elimination by autophagy. EMBO J. 2008;27:433-446.

37. Baburamani AA, Hurling C, Stolp H, Sobotka K, Gressens P, Hagberg H, Thornton C. Mitochondrial optic atrophy (OPA) 1 processing is altered in response to neonatal hypoxicischemic brain injury. Int J Mol Sci. 2015;16:22509-22526.

38. Sanderson TH, Raghunayakula S, Kumar R. Neuronal hypoxia disrupts mitochondrial fusion. Neuroscience. 2015;301:71-8.

39. Sharp WW, Fang YH, Han M, Zhang HJ, Hong Z, Banathy A, Morrow E, Eyan JJ, Archer SL. Dynamin-related protein 1 (Drp1)-mediated diastolic dysfunction in myocardial ischemia-reperfusion injury: therapeutic benefits of Drp1 inhibition to reduce mitochondrial fission. FASEB J. 2014;28:316-326.

40. Oppenheim RW, Blomgren K, Ethell DW, Koike M,
Komatsu M, Prevette D, Roth KA, Uchiyama Y, Vinsant $\mathrm{S}$ and Zhu C. Developing postmitotic mammalian neurons in vivo lacking Apaf-1 undergo programmed cell death by a caspase-independent, nonapoptotic pathway involving autophagy. J Neurosci. 2008;28:1490-1497.

41. Komatsu M, Waguri S, Chiba T, Murata S, Iwata J, Tanida I, Ueno T, Koike M, Uchiyama Y, Kominami E and Tanaka $\mathrm{K}$. Loss of autophagy in the central nervous system causes neurodegeneration in mice. Nature. 2006;441:880-884.

42. Ravikumar B, Sarkar S, Davies JE, Futter M, GarciaArencibia M, Green-Thompson ZW, Jimenez-Sanchez M, Korolchuk VI, Lichtenberg M, Luo S, Massey DC, Menzies FM, Moreau K, et al. Regulation of mammalian autophagy in physiology and pathophysiology. Physiol Rev. 2010;90:1383-1435.

43. Li Q, Li H, Roughton K, Wang X, Kroemer G, Blomgren $\mathrm{K}$, Zhu C. Lithium reduces apoptosis and autophagy after neonatal hypoxia-ischemia. Cell Death Dis. 2010;1:e56.

44. Marino G, Pietrocola F, Madeo F, Kroemer G. Caloric restriction mimetics: natural/physiological pharmacological autophagy inducers. Autophagy. 2014;10:1879-1882.

45. Koike M, Shibata M, Tadakoshi M, Gotoh K, Komatsu M, Waguri S, Kawahara N, Kuida K, Nagata S, Kominami $\mathrm{E}$, Tanaka $\mathrm{K}$ and Uchiyama Y. Inhibition of autophagy prevents hippocampal pyramidal neuron death after hypoxic-ischemic injury. Am J Pathol. 2008;172:454-469.

46. Zhu C, Wang X, Huang Z, Qiu L, Xu F, Vahsen N, Nilsson M, Eriksson PS, Hagberg H, Culmsee C, Plesnila N, Kroemer G, Blomgren K. Apoptosis-inducing factor is a major contributor to neuronal loss induced by neonatal cerebral hypoxia-ischemia. Cell Death Differ. 2007;14:775784.

47. Galluzzi L, Blomgren K, Kroemer G. Mitochondrial membrane permeabilization in neuronal injury. Nat Rev Neurosci. 2009;10:481-494.

48. Dimlich RV, Kaplan J, Timerding BL, Van Ligten PF. Effects of various doses of sodium dichloroacetate on hyperlactatemia in fed ischemic rats. Ann Emerg Med. 1989;18:1162-1171.

49. Kaufmann P, Engelstad K, Wei Y, Jhung S, Sano MC, Shungu DC, Millar WS, Hong X, Gooch CL, Mao X, Pascual JM, Hirano M, Stacpoole PW, et al. Dichloroacetate causes toxic neuropathy in MELAS: a randomized, controlled clinical trial. Neurology. 2006;66:324-330.

50. Han W, Sun Y, Wang X, Zhu C, Blomgren K. Delayed, long-term administration of the caspase inhibitor Q-VD$\mathrm{OPh}$ reduced brain injury induced by neonatal hypoxiaischemia. Dev Neurosci. 2014;36:64-72.

51. Li H, Li Q, Du X, Sun Y, Wang X, Kroemer G, Blomgren $\mathrm{K}$, Zhu C. Lithium-mediated long-term neuroprotection in neonatal rat hypoxia-ischemia is associated with antiinflammatory effects and enhanced proliferation and survival of neural stem/progenitor cells. J Cereb Blood Flow Metab. 2011;31:2106-15. 
52. Gubern C, Hurtado O, Rodriguez R, Morales JR, Romera VG, Moro MA, Lizasoain I, Serena J and Mallolas J. Validation of housekeeping genes for quantitative real-time PCR in in-vivo and in-vitro models of cerebral ischaemia. BMC Mol Biol. 2009;10:57. 